\title{
A LIBERDADE E A IGUALDADE NAS TEORIAS DA DEMOCRACIA NOS SÉCULOS XVIII E XIX
}

MARIA JOSÉ DE REZENDE

Prof ${ }^{a}$. do Departamento de Ciências Sociais da Universidade Estadual de Londrina

\begin{abstract}
O objetivo deste artigo é apresentar algumas reflexões acerca da democracia nos séculos XVIII e XIX. Acredita-se que a reflexão sobre as inúmeras teorizações é de grande importância na medida em que somente ela pode revelar os percalços e os caminhos inusitados que a democracia percorreu e continua a percorrer. A construção de inúmeros significados para a democracia dialoga, de alguma forma, com as diversas indagações que se desenvolveram no transcorrer dos tempos. A constante reelaboração destes significados não se dá num vazio, uma vez que ela recorre permanentemente a uma enorme herança teórica que tem se formado no transcorrer dos séculos.
\end{abstract}

Palavras chaves: democracia, liberdade política, igualdade, propriedade, sufrágio universal, maioria, minoria, representação.

\section{DEMOCRACIA: ASPECTOS} GERAIS DE UMA DISCUSSÃO QUE FLORESCEU NO SÉCULO XVIII.

$\mathrm{T}$ em sido comum considerar o século XVIII ${ }^{1}$ como o marco fundamental da discussão em torno da democracia no mundo moderno. ${ }^{2}$ Faz-se necessário, no entanto, destacar que a democracia é uma questão que esteve $^{3}$ presente, através dos tempos, no constante desafio ao pensamento e à ação dos homens no que tange às suas inúmeras relações.

Dentre os diversos aspectos das teorizações sobre a democracia que floresceram no século XVIII, serão enfatizadas duas questões que têm perpassado a história da democracia no mundo moderno: a liberdade e a igualdade.

Em termos gerais, a título de contextualização da discussão sobre a democracia no século XVIII, faz-se necessário destacar que a questão fundamental naquele momento, na Europa principalmente, era o debate sobre a democracia como forma de governo não-despótica. Nessas condições, ganhou relevo o problema da relação democracia e república.
Montesquieu, com a obraO Espírito das Leis, escrita em 1748, pode ser tomado como o exemplo mais significativo da preocupação dominante, naquela época, em definir formas de governo, as quais poderiam ser republicana, monárquica ou despótica. Em Montesquieu, a "república compreende (...) tanto a aristocracia quanto a democracia, conforme o poder seja exercido por 'todo o povo' ou só uma parte." (BOBBIO, 1980, p.120)

A igualdade e a liberdade possuíam um lugar fundamental na teoria de Montesquieu, ambas tematizadas como forma de destacar a necessidade de prevalência da lei, pois, para ele, a democracia se arruinaria, se o povo não reconhecesse a lei como o seu fundamento. Montesquieu argumentava que a "virtude, nas repúblicas, não é senão o amor da pátria, isto é, da igualdade - não uma virtude moral, ou cristã mas sim política: a mola que impulsiona o governo republicano, como a honra é a mola que impulsiona a monarquia. Chamei portanto de virtude política o amor da pátria e da igualdade".(MONTESQUIEU, 1973, p.69-85)

A república democrática era pensada por Montesquieu, segundo Bobbio, a partir do conceito de igualdade. Ou seja, era o que a distinguia de "outras formas de governo, fundamentadas na desigualdade irredutivel entre governantes $e$ governados e na irredutivel desigualdade entre os próprios governados." (BOBBIO, 1980, p.123). A 
liberdade e a lei eram indissociáveis para Montesquieu, ou seja, a primeira era definida e limitada pela segunda. A liberdade estava respaldada nas leis e era concebida como circunscrita ao que estas permitissem. A separação dos poderes, no entanto, é que fornecia os elementos para a sua discussão em torno da liberdade política. $\mathrm{O}$ abuso do poder era, para ele, sinônimo de desrespeito às leis e, também, de não-separação dos poderes, os quais inibiam qualquer possibilidade de liberdade política.

A tematização em torno da liberdade e da igualdade, no século XVIII, encontrou em Rousseau um dos seus mais importantes teóricos. O teórico da formação da vontade geral inalienável trouxe para o centro do debate essas duas questões que têm atravessado os séculos como o grande problema da democracia.

No final do século XVIII e início do século XIX, havia na Europa duas concepções: a liberal e a democrática. Luciano Gruppi (GRUPPI, 1985) afirma que a primeira defendia a correlação entre propriedade e liberdade (isto é, a liberdade exige a desigualdade), e a segunda pautava-se na idéia de que a liberdade baseia-se na igualdade ${ }^{4}$, essencialmente na igualdade jurídica ${ }^{5}$ (embora Rousseau (ROUSSEAU, 1978) colocasse o problema da propriedade).

Para Rousseau, apenas o "direito limitado (de propriedade) era consistente com a soberania da vontade geral. Uma sociedade verdadeiramente democrática, uma sociedade governada pela vontade geral ${ }^{6}$ exige essa igualdade de propriedade". (MACPHERSON, 1978, p.23) No livro II de O contrato social, Rousseau esclarece o significado da vontade geral que "tende sempre para a utilidade pública" para o interesse comum; é neste aspecto, principalmente, que ela se diferencia da vontade de todos que visa sempre o interesse privado.

Um dos méritos de Rousseau e o que exige o constante reportar à sua discussão como um dos marcos da teoria da democracia na era moderna, não é, por certo, porque ele advogava qualquer facilidade no processo de constituição de uma sociedade democrática. Pelo contrário, tanto em $\mathbf{O}$ contrato social quanto em Discurso sobre a origem e os fundamentos da desigualdade entre os homens, Rousseau explicitava as enormes dificuldades de estabelecimento da verdadeira democracia.
Ressalte-se que esta última era por ele definida a partir de um conjunto de condições que envolviam elementos de todas as ordens, tais como: jurídica, social, natural, política e econômica. Os aspectos jurídicos ganharam, nas suas discussões, um estatuto fundante da ordem democrática, o que tem de ser visto a partir das condições prevalecentes na Europa, no século XVIII. Conforme afirmava Marshall (MARSHALL, 1967, p.63-9) a defesa dos direitos civis era, naquele momento, um passo indiscutivelmente importante para a formação dos direitos políticos no século seguinte. ${ }^{7}$

$\mathrm{Na}$ discussão sobre as formas de governo, Rousseau argumentava que a democracia poderia "abarcar todo o povo, ou então restringir-se até a metade"; (ROUSSEAU, 1978 , p.72) o que apontava para a complexidade de estabelecer as condições políticas mínimas para a verdadeira democracia. Estas, por sua vez, tinham implicações de ordem jurídica e social.

" $O$ sistema político descrito em $\boldsymbol{O}$ contrato social não é uma democracia segundo o uso que Rousseau faz do termo. Para ele, 'democracia' seria um sistema onde os cidadãos são executores de leis que eles mesmos fizeram (sistema direto $e$ não representativo) $e$, por esse motivo, seria um sistema próprio para os deuses". (PATEMAN, 1992, p.35) Rousseau afirmava que, "rigorosamente falando, nunca existiu verdadeira democracia nem jamais existirá. (...) Se houvesse um povo de deuses, ele se governaria democraticamente. Tão perfeito governo não convém aos homens".(ROUSSEAU, 1978 , p.735)

Ressalte-se que essa afirmação de Rousseau não significava descrença nas possibilidades da democracia, tanto que toda a sua obra destacou a necessidade de criação das bases para que o Estado se tornasse o mais democrático possível. A máxima participação ${ }^{8}$ do indivíduo no processo político era a condição fundamental para se alcançar este objetivo.

Em termos gerais, pode-se afirmar que praticamente toda a preocupação de Rousseau, especialmente em $\mathbf{O}$ contrato social, está ligada à necessidade de desenvolvimento de uma sociedade em que as diferenças sociais (que não deviam ser muito grandes) não levassem às desigualdades políticas. Isto seria um dos princípios básicos da democracia.

Ainda no século XVIII, a relação entre liberdade e igualdade foi também uma questão 
central nos escritos de Thomas Jefferson (JEFFERSON, 1979, p.01-40) para quem "a democracia exigia uma sociedade em que todos fossem economicamente independentes", isto porque "sua confiança no povo era confiança no proprietário trabalhador independente, (que ele via) como a espinha dorsal, e esperava que permanecesse a espinha dorsal da sociedade americana." (JEFFERSON, 1979, p.24-5).

Anthony Arblaster, em A democracia, assinala que o objetivo de Jefferson não era a democracia, mas o governo limitado, ou seja, a república representativa. Na mesma linha estaria Hamilton (federalista americano), para quem a democracia representativa (HAMILTON, 1979) evitava os perigos obviamente inerentes à democracia simples. Estes pensadores elaboravam, segundo Arblaster, uma versão de democracia como alternativa à concepção de governo popular. (ARBLASTER, 1988, p.66)

Norberto Bobbio, numa outra linha de análise, argumenta que os federalistas estavam preocupados com a questão da democracia, mas viam que a única democracia adequada era a representativa. (BOBBIO, 1988, p.33) Uma forma "de governo em que o povo não toma ele mesmo as decisões que lhe dizem respeito, mas elege seus próprios representantes, que devem por ele decidir. Mas não pensavam realmente que instituindo uma democracia representativa acabariam por enfraquecer o princípio do governo popular". (BOBBIO, 1988, p.33-4)

Rousseau e Jefferson exerceram influências básicas nas construções de modelos e formas de se pensar a democracia na atualidade. Saliente-se, porém, que James Madison ${ }^{10}$ "foi tão influente quanto Jefferson, se não mais ainda, no pensamento americano: Robert Dahl, por exemplo, elabora seu modelo de democracia no século XX amplamente (apoiado) sobre Madison". (MACPHERSON, 1978, p.22) Um dos elementos básicos da teoria de Madison (MADISON, 1979, p.87-181) sobre a democracia é o problema da acomodação entre o poder das maiorias e o das minorias. As questões da igualdade política e da soberania aparecem, então, como centrais.

Robert Dahl afirma que a proposição fundamental da teoria madisoniana é a seguinte: na ausência de controles externos, qualquer indivíduo ou grupo de indivíduos tiranizará os demais. Isto pressupõe a necessidade desses controles externos que consistem na aplicação de recompensas e penalidades ou, pelo menos, a existência da expectativa de que serão aplicadas por alguma outra fonte que não ele mesmo.

A compreensão da posição de Madison sobre a democracia requer, obviamente, que a atenção seja voltada para a problemática que atormentava diversos constitucionalistas americanos no século XVIII: o risco da tirania da maioria e/ou das minorias. Nessas condições, Madison discutia as formas de evitar as facções, prevenir-lhe as causas, ou corrigir-lhe os efeitos. ${ }^{11}$

A preocupação de Madison era a necessidade de diferenciar o que ele denominava democracia pura e governo representativo. A primeira seria composta de um pequeno número de cidadãos, que se reuniriam e governar-se-iam por si mesmos. Nas democracias puras teriam prevalecido as dissensões e a desordem, uma vez que esta forma de governo seria incompatível, observa Madison, (MADISON, 1979 , p.97) com a conservação do direito de propriedade, especialmente.

Madison argumentava que o governo representativo (ou república) diferenciava-se da democracia pura, principalmente, pela maior abrangência do número de cidadãos. Mas o seu traço essencial estaria na forma de "poderes delegados a um pequeno número de indivíduos que o povo escolhe".(MADISON, 1979, p.98)Os pressupostos da teoria madisoniana da democracia foram apenas indicados aqui com a intenção de destacar que, sobre esses pilares, floresceram inúmeras discussões. No século XX, por exemplo, não é possível apreender os aspectos básicos da teoria da democracia, no que tange, principalmente, às abordagens pluralistas $\mathrm{e}$ elitistas sem passar pelos escritos de Madison.

A questão maioria/minoria, uma das principais preocupações de Madison, sempre esteve no centro do debate político sobre a democracia ${ }^{12}$ no século XX. As discussões de Dahl, Eckstein, Berelson, etc., resguardando as suas diferenças, deixam evidentes as influências de Madison.

\section{ASPECTOS GERAIS DA TEORIZAÇÃO DA DEMOCRACIA No SÉCULO XIX.}

Inúmeras reflexões acerca da democracia ganham fôlego durante o século XIX. Diversos 
teóricos da primeira metade deste século expressavam claramente os desafios que se colocavam naquele momento e o grau de complexidade cada vez maior que a problemática da democracia ia assumindo.

Com Bentham e James Mill, assiste-se ao florescimento de uma posição que Macpherson chamou de ética humanista. Dentre as questões enfatizadas, estavam a proteção aos governados (Bentham e James Mill) e a possibilidade de desenvolver a capacidade humana que teve sua máxima nos escritos de John Stuart Mill. ${ }^{13} \mathrm{~A}$ análise de Bentham sobre a democracia está ancorada no homem como um ser moral e social. O aperfeiçoamento do regime democrático era tido por ele como algo essencial para o desenvolvimento do homem nos dois aspectos acima considerados.

Os pressupostos da democracia em Bentham têm que ser destilados de sua discussão em torno do princípio da autoridade. ${ }^{14} \mathrm{~A}$ obra Uma introdução aos princípios da moral e da legislação (BENTHAM, 1979), de 1789, ao buscar explicar a constituição da conduta individual e social, apresenta as melhores pistas para se captar uma concepção de democracia que estava florescendo no século XIX: a democracia ${ }^{15}$ liberal.

Com as posições de Bentham e James Mill, começou a delinear-se uma nova forma de conceber a relação entre o sufrágio universal e a propriedade. Ou seja, neste momento, o primeiro vai deixando de ser visto como a grande ameaça à segunda. Evidentemente que havia ainda enormes restrições ao sufrágio universal. Os dois pensadores aqui mencionados, encontraram grande dificuldade para lidar com esta questão. Bentham, somente no final de sua vida, defendia o sufrágio universal. James Mill se propôs a defendê-lo, mas impunha muitas restrições, de forma que inúmeros indivíduos ficavam fora deste direito político.

Bentham desenvolveu uma discussão sobre a segurança, a igualdade e a propriedade que pode ser considerada um dos pilares da democracia liberal que ganhou fôlego na segunda metade do século XIX. A forma de lidar com o princípio da propriedade dava, à sua teoria, um sentido singular para a relação propriedade e igualdade. Para Macpherson (MACPHERSON, 1978, p.38) a primeira teria, nos escritos de Bentham, supremacia absoluta sobre a segunda.

A contribuição maior de Bentham para a teoria da democracia desenvolvida no século XIX foi a sua discussão sobre o tipo de Estado e de sistema político capaz de proteger os governados. "Tratavase de um duplo problema: o sistema político devia produzir governos que tanto estabelecessem e fomentassem uma sociedade de mercado livre quanto protegessem os cidadãos contra governos rapaces (...)." (MACPHERSON, 1978, p.39) Ressalte-se que, para Bentham, a proteção aos cidadãos era o objetivo básico do sistema democrático, que deveria se pautar num governo representativo e assentado sobre franquias. ${ }^{16}$

James Mill, assim como Bentham, deu uma enorme contribuição para a discussão em torno da democracia no século XIX. É preciso ressaltar, no entanto, que, mesmo ele se reportando a uma franquia universal, não desapareciam as exclusões de parte significativa dos indivíduos da possibilidade de atuação no sistema político. Carole Pateman, em Participação e teoria democrática, ameniza os traços de exclusão das teorias de Bentham e James Mill. Para ela, a noção de povo como classe numerosa implicava numa abrangência significativa. Macpherson, no entanto, emA democracia liberal, ressalta o alto nível de restrição que o sistema por franquias impunha.

As teorias da democracia ganharam fôlego no século XIX com a contribuição de John Stuart Mill que se debateu entre a função de um governo democrático de proteção aos governados e a de atuar sobre a mente humana para desenvolver a sua capacidade. Ele "encara o governo e as instituições políticas, em primeiro lugar e acima de tudo, como educativos no sentido mais amplo do termo.(...) (e) Apenas vê a possibilidade de desenvolvimento de um tipo de caráter ativo, de espírito público, no contexto de instituições populares, participativas". (PATEMAN, 1992. P.43-4)

J.S.Mill formulou sua discussão em torno da democracia, levando em consideração a ampla movimentação da classe trabalhadora em meados do século XIX. Naquelas condições, ele advogava a necessidade de desenvolver a mente de todos os membros da sociedade para se alcançar o aperfeiçoamento de um sistema político democrático.

Para John Stuart Mill "um sistema político democrático é avaliado como meio para aquele aperfeiçoamento - meio necessário conquanto não suficiente; e uma sociedade democrática é vista como resultado daquele aperfeiçoamento e ao mesmo tempo como meio de mais aperfeiçoamento" (PATEMAN, 1992, p.52). A teoria democrática de J. S. Mill destaca 
especialmente as possibilidades de desenvolvimento da capacidade humana. Uma sociedade democrática era aquela que permitisse que isto ocorresse de fato.

Em Governo Representativo, (MILL, 1964), J S Mill esclarecia algumas de suas preocupações quanto à forma de se chegar a essa sociedade democrática. A sua exposição concentrava-se no estabelecimento de um sistema político ${ }^{17}$ onde não prevalecesse o egoísmo tanto da minoria quanto da maioria. Ou seja, o sistema de voto plural (um voto para todos, mas vários votos para alguns) visava, segundo ele, evitar a imposição de uma maioria ${ }^{18}$ para uma minoria.

O elemento básico a ser destacado na análise de J.S.Mill é que seu modelo de democracia enfatizava a necessidade de participação dos membros da sociedade como fator de aperfeiçoamento da democracia. Não há possibilidade, neste artigo, de se discutir as ambigüidades da noção de participação em J.S.Mill. Carole Pateman, (PATEMAN, 1992, p.42), analisa substancialmente os elementos da teoria da democracia participativa neste pensador, bem como aponta para as suas dificuldades.

Em termos gerais, J. S. Mill considerava que "a participação no governo local é uma condição necessária para a participação a nível nacional, devido a seu efeito educativo ou aperfeiçoador, assim também Mill sugere que a participação no governo do local de trabalho teria o mesmo impacto". (PATEMAN, 1992, p.51) Estas questões esclarecem a preocupação de J.S.Mill com as condições vivenciadas naquele momento, em que a classe trabalhadora se colocava na arena política com inúmeras exigências e reivindicações, ou seja, num movimento significativo por melhores condições de existência.

A obra de J.S.Mill representou, em meados do século XIX, o encontro entre a teoria democrática e a teoria liberal. Suas discussões expressavam as transformações sociais, econômicas e políticas pelas quais passava a sociedade da época. Maurice Duverger afirma que as transformações industriais do início do século XIX acabaram por destruir o sistema aristomonárquico e, a partir de meados do século em questão, tomou corpo a democracia liberal. (DUVERGER, 1975, p.56)

Afirmações desta natureza desfazem a concepção equivocada de que a democracia liberal nasceu com o liberalismo. Para Sartori, o "ideal liberal e o democrático mesclaram-se, e essa mescla fez-se confusa". (SARTORI, 1965, p.367)
A democracia liberal se constituiu num momento histórico em que a questão da democracia, como participação do homem comum nas questões do Estado, era algo fundamental. (HOBSBAWN, 1982, p.117) Segundo Hobsbawn, a fusão do liberalismo com a democracia era uma necessidade, uma vez que se tinha, por um lado, a democracia como uma força histórica reconhecida, e, por outro, o liberalismo na sua forma de organização política que representava "agregados de indivíduos de status legalmente iguais".(HOBSBAWN, 1982, p.117)

O credo das massas, afirma Hobsbawn, tinha que ser levado em conta na política. "Eles eram por definição numerosos, ignorantes e perigosos; muito perigosos, precisamente devido à sua ignorante tendência para acreditar em seus próprios olhos, que lhes diziam que aqueles que os governavam davam muito pouca atenção a suas misérias, e a lógica simplista que lhes sugeria que, já que eles formavam a grande maioria do povo, o governo deveria basicamente servir-lhes em seus interesses". (HOBSBAWN, 1982, p.117)

A partir de meados do século XIX ficava claro que as massas poderiam "irromper no círculo fechado dos dirigentes da sociedade" (HOBSBAWN, 1982, p.118), portanto, ficava "cada dia mais claro nos países desenvolvidos $e$ industrializados (...), que mais cedo ou mais tarde os sistemas políticos teriam que abrir espaço para estas forças". (HOBSBAWN, 1982, p.118) A democracia liberal preocupa-se, então, em definir sua organização política baseada na soberania popular, cidadania, eleições, independência de juizes, liberdades políticas, pluralismo de partidos, etc..

$\mathrm{O}$ contexto sócio-econômico e político, na Europa, na segunda metade do século XIX, foi marcado pelas diversas formas de organização dos trabalhadores; o que se constituía, sem nenhuma dúvida, num elemento básico no redimensionamento das pressuposições em torno da democracia.

Nas cinco últimas décadas do século XIX, no entanto, o liberalismo viu-se desafiado: o seu compromisso extremo com o mercado (DUVERGER, 1975) deixava-o numa situação absolutamente difícil ante as exigências de reformas sociais e políticas que a classe trabalhadora fazia de forma cada vez mais contundente.

Assiste-se ao culminar do processo que se iniciou nas primeiras décadas do século XIX: a adaptação dos princípios fundamentais do liberalismo às exigências e demandas das classes dominadas. A democracia liberal significava a busca 
de caminhos para uma sociedade que contava com uma crescente reivindicação das massas.

Segundo Sartori e Gruppi, em meados do século XIX, a democracia fundiu-se com o liberalismo. Tocqueville, assinalam eles, (TOCQUEVILLE, 1977) foi a expressão mais importante deste processo de fusão. "A feliz conjuntura histórica que os obrigava a reunir-se apagou as suas respectivas fronteiras $e$, portanto, acarretou uma variação de atribuições, dependendo de se um escritor está mais interessado em conservar a democracia na órbita do liberalismo, ou em remontar à passagem do liberalismo a democracia". (SARTORI, 1965. P.367)

A contribuição de Alexis de Tocqueville para a discussão sobre a democracia é inegável. Ele "estava firmemente convencido de que a liberdade, principalmente a liberdade religiosa e moral (mais que a econômica), era o fundamento e o fermento de todo poder civil. Mas havia compreendido que o século nascido da revolução caminhava impetuosamente e inexoravelmente em direção à democracia. Era um processo incontrolável". (BOBBIO, 1988, p.56)

Tocqueville considerava a democracia forte $o$ suficiente para resistir a qualquer ameaça. "Talvez cause admiração o fato de (...) (adotarmos) firmemente a opinião de que a revolução democrática de que somos testemunhas é um fato irresistivel contra o qual não seria nem desejável nem prudente lutar (...)." (TOCQUEVILLE, 1977. P.319)

A democracia, para Tocqueville, precisava ser educada, seus costumes deviam ser purificados, seus movimentos necessitavam ser regulados, seus instintos cegos tinham que ser controlados. A sua análise sobre A democracia na América, objetiva enfatizar " a direção que a democracia, (...) entregue às suas inclinações $e$ abandonada quase sem restrições aos seus instintos, dava naturalmente às leis, a marcha que imprimia ao governo e, em geral, a influência que exercia sobre os negócios do Estado". (TOCQUEVILLE, 1977, p.19)

Tocqueville estava preocupado em detectar em que sentido os americanos estavam educando, purificando, controlando os movimentos da democracia, ou seja, "quais eram as precauções tomadas (...) para dirigi-la (...) (e quais) as causas que lhe permit(iam) governar a sociedade" (TOCQUEVILLE, 1977, p.19).
O livro $\Pi$ de A democracia na América, tinha como objetivo mostrar "a influência que a igualdade e o governo da democracia exercem sobre a sociedade civil, sobre os hábitos, as idéias e os costumes" (TOCQUEVILLE, 1977, p.19) . Desta forma, ele indagava sobre as possibilidades de a liberdade sobreviver ou não em uma sociedade cujo sistema exaltava o valor da igualdade não apenas política, mas também social.

A preocupação básica de Tocqueville, no livro II, era com a possibilidade de que a igualdade desejada pela humanidade destruísse a liberdade(GRUPPI, 1985.p.45). Ele assinalava que caso isto ocorresse ao invés da realização da democracia, teríamos a tirania.

"É claro que se cada cidadão, na medida em que se tornasse individualmente mais fraco e, por conseguinte, mais incapaz de preservar isoladamente sua liberdade, não aprendesse a unirse a seus semelhantes para defendê-la, a tirania cresceria necessariamente com a igualdade". (TOCQUEVILLE, 1977, p.287) Ressalte-se que, para Tocqueville, da mesma forma que não era admissível que todo o poder estivesse centrado nas mãos de uma só pessoa, não podia ser desejável também que todo o poder fosse atribuído a vários indivíduos. Tanto no primeiro caso, quanto no segundo, haveria a perda da liberdade.

Os danos para a liberdade seriam tão funestos numa sociedade onde prevalecesse a tirania de um quanto a tirania da maioria. "Acredito, pois, que é sempre necessário situar em alguma parte um poder social superior a todos os demais; mas também creio que a liberdade está em perigo quando esse poder não tem à sua frente nenhum obstáculo que possa deter a sua marcha e dar-lhe o tempo de se moderar". (TOCQUEVILLE, 1977, p.194)

$\mathrm{O}$ poder extremo era perigoso em toda e qualquer circunstância. Tocqueville afirmava: "Quando, pois, vejo concedido o direito e a faculdade de tudo fazer a um poder qualquer, seja ele o povo ou o rei, a democracia ou a aristocracia, exercido numa monarquia ou numa república, eu afirmo: está ali o germe da tirania (...)".(TOCQUEVILLE, 1977, p.194)

A sua crítica à democracia americana era no sentido de que a vontade da maioria havia se transformado numa força irresistível e, desta forma, tinha-se pouca garantia contra a tirania. E mesmo que não se fizesse uso freqüiente da tirania nos Estados Unidos, não havia uma internalização 
contrária aos excessos que o despotismo da maioria poderia causar.

O risco da tirania da maioria, no entanto, poderia ser amenizado, em toda sociedade, inclusive na América, se um corpo legislativo fosse composto de forma que representasse a maioria, mas que nunca fosse escravo de suas paixões; "um poder executivo que tenha uma força que lhe seja própria, e um poder judiciário independente dos dois outros poderes (...)".(TOCQUEVILLE, 1977, p.195) A igualdade política e/ou social, afirmava Alexis de Tocqueville, era sempre demonstrada como um dos bens mais promissores dos homens, no entanto, poucos compreendiam o quanto esta poderia se tornar ameaçadora.

A igualdade, segundo ele, "pode estabelecerse na sociedade civil e não reinar no mundo político. Pode-se ter o direito de se entregar aos mesmos prazeres, de entrar para as mesmas profissões, de encontrar-se nos mesmos lugares; numa palavra, de viver da mesma maneira e de procurar a riqueza pelos mesmos meios, sem tomar todos a mesma parte do governo. Pode estabelecer-se mesmo uma espécie de igualdade no mundo político, embora não haja a liberdade política. Somos iguais a todos os nossos semelhantes, menos um, que é, sem distinção, o senhor de todos, eque toma igualmente, entre todos, os agentes do seu poder." (TOCQUEVILLE, 1977, p.384)

Os povos democratas apreciam a liberdade, sem nenhuma dúvida, mas têm verdadeira paixão pela igualdade, argumenta Tocqueville. $O$ sentimento de igualdade seria, no século XIX, pleno de singularidade, ou seja, algo que os homens encaram como a maior de suas conquistas, o maior bem que se poderia almejar. "Eu acredito que os povos democráticos têm um gosto natural pela liberdade; entregues a si mesmos, procuram-na e se entristecem quando lhes é tirada. Mas têm pela igualdade uma paixão ardente, insaciável, eterna, invencível; desejam a igualdade dentro da liberdade, e, se não a podem obter, ainda a desejam na escravidão". (TOCQUEVILLE, 1977, p.3856)

A liberdade e a igualdade não se confundem, ou seja, não é possível afirmar que a existência de uma fatalmente implicará na da outra. A liberdade, afirma Tocqueville, "manifestou-se aos homens em diferentes ocasiões e sob diferentes formas; nunca se ligou exclusivamente a um estado social e podemos encontrá-la também fora das democracias". (TOCQUEVILLE, 1977, p.384)
Alexis de Tocqueville, no entanto, na quarta parte do segundo livro de A democracia na América, ao discutir a influência das idéias e dos sentimentos democráticos na sociedade política, destaca os aspectos positivos da igualdade, uma vez que esta desenvolve nos homens o gosto pelas instituições livres.

Ressalte-se que, dentre os efeitos políticos produzidos pela igualdade, está o apreço às instituições livres, o que pode conduzir à anarquia, mas, afirma Tocqueville, "estou convencido, porém, que a anarquia não é o principal mal que os séculos democráticos devem temer, mas o menor. A igualdade produz, com efeito, duas tendências: uma conduz os homens diretamente à independência e os pode impelir de repente para a anarquia; a outra os conduz por um caminho mais longo, mais secreto, mais seguro, para a servidão." (TOCQUEVILLE, 1977, p.512)

Fica, portanto, evidenciado que Tocqueville, mesmo destacando os efeitos positivos da igualdade, não deixa de considerá-la sob o seu aspecto negativo que é a possibilidade de que ela conduza à servidão, ou seja, à tirania da maioria.

Norberto Bobbio afirma que "na linguagem de Tocqueville 'democracia' significa, por um lado, (...) forma de governo ${ }^{19}$ em que todos participam da coisa pública, o contrário de aristocracia; por outro lado, significa a sociedade que se inspira no ideal da igualdade e que, ao se entender, acabará por submergir as sociedades tradicionais fundadas sobre uma ordem hierárquica imutável". (BOBBIO, 1988. p.56)

A democracia, como forma de governo, seria uma constante ameaça para Tocqueville, afirma Bobbio. "O perigo que a democracia corre como progressiva realização do ideal igualitário é o nivelamento, cujo efeito final é o despotismo. São duas formas diversas de tirania, e, portanto, ambas, embora de maneira diversa, são a negação da liberdade".(BOBBIO, 1988, p.57)

Os pressupostos acerca da democracia desenvolvidos nos séculos XVIII e XIX constituíram-se em alicerces sobre os quais se desenvolveu uma ampla reflexão no século seguinte. Os rumos que tomaram as inúmeras indagações durante o século XX merecem, certamente, um outro artigo. 
1 Macpherson afirma que nos "séculos XVI e XVII encontramos teorias democráticas explícitas. Duas correntes democráticas aparecem então na Inglaterra. Uma delas tem como base uma sociedade sem classes (More e Westanley) e a outra uma sociedade de classe única (niveladores)." MACPHERSON, C.B. A democracia liberal. Rio de Janeiro, Zahar, 1978. p.20

2 Pode-se afirmar que as teorizações acerca da tradição aristotélica das três formas de governo (idade antiga) e a teoria romano-medieval da soberania popular (idade média) expressavam o constante pulsar do processo de invenção da democracia. Esta última desempenhou um papel fundamental nas formulações da teoria moderna da democracia. A teoria contratualista, que foi elaborada entre o início do século XVII e o final do século XVIII, tomou como ponto de partida a herança da teoria romano-medieval da soberania popular, a qual argumentava que devia pertencer ao povo o poder de fazer as leis em que o poder soberano se apoiava. A teoria contratualista, não querendo desconsiderar sua enorme complexidade, tinha como objetivo o alicerçamento do poder no consenso, o que esclarece o seu importante papel nas teorias da democracia que se desenvolveram posteriormente.

3 Análises sobre a democracia antiga podem ser encontradas em: FINLEY, M. I. A democracia antiga e moderna. Rio de Janeiro, Graal, 1988. ARBLASTER, A. A democracia. Lisboa, Estampa, 1988. DAVIES, J. K. Democracy and classical Greece. Londres, Fontana, 1978. FORREST, W. G. The emergence of greek democracy. Londres, Weidenfeld \& Nicolson, 1966. JONES,A.H.M.Athenian democracy. Oxford, Basil Blackwell, 1957

4 A igualdade para Rousseau funda-se na soberania da vontade geral.

5 Rousseau afirma: "As leis são sempre úteis àquele que possui e danosa àqueles que nada têm: do que se segue que o Estado social é vantajoso aos homens apenas quando eles tenham alguma coisa e ninguém tenha demasiado." ROUSSEAU, J. J. O contrato social. São Paulo, Cultrix, 1978. p. 34

6 A discussão de James Madison sobre a vontade geral é também muito importante. Ver: MADISON, J. Utilidade da união como preservativo contra as facções e insurreições. In Os pensadores. São Paulo, Abril,p.95-100.

7 A problemática dos direitos civis, políticos e sociais foram discutidos em:MARSHALL,T.H. Cidadania, classe social e status. Rio de Janeiro, Zahar, 1967. p. 63-89.

8 Sobre a teoria da participação em Rousseau, ver: PATEMAN, op. cit., p.35-47

9 Hamilton dizia: "Dêem todo o poder aos muitos e eles oprimirão os poucos. Dêem todo o poder aos poucos e eles oprimirão os muitos". Citado em: DAHL, R. Um prefácio à teoria democrática. Rio de Janeiro, Zahar, 1989. p.16

${ }^{10}$ Há grandes diferenças entre Rousseau e os constitucionalistas americanos. Pode-se dizer que Rousseau concordava com Madison, por exemplo, em que as decisões da maioria não eram sempre corretas. No entanto, as soluções apontadas, entre eles, eram diversas. Para os constitucionalistas, era preciso dividir o controle institucional sobre a vontade da maioria. A teoria da vontade geral de Rousseau era absolutamente diferente, ou seja, a maioria teria que representar a comunidade como um todo e não apenas interesses de grupos. ARBLASTER, op. cit., p.68/9

11 MADISON, J. Utilidade da união como preservativo contra as facções e insurreições. In Os pensadores, São Paulo, Abril, 1979. p. 94-100. Dahl afirma que a definição de Madison de facção é a seguinte: “(...) é certo número de cidadãos, seja equivalente a uma maioria ou minoria do todo, unidos e motivados por algum impulso comum de paixão, ou de interesses, contrário aos direitos dos demais cidadãos ou aos interesses permanentes e conjuntos da comunidade". DAHL, op. cit., p.22
12 No século XX floresceram inúmeras discussões em torno das formas de restrições às maiorias (controles sociais, controles constitucionais, etc.). Anthony Arblaster afirma que o reaparecimento da democracia moderna deve ser relacionado ao medo perante as massas, a multidão, que vai estar constantemente presente nas diversas indagações sobre a democracia. Ao mesmo tempo em que as reivindicações das massas devem ser vistas como impulso para as teorias democráticas, elas precisam, também, ser pensadas como as bases para o surgimento de posições que objetivam afastar os riscos da democracia como o governo do povo. ARBLASTER, op. cit., p.45 et. seq.

13 J.S. Mill tenta, diz Arblaster, conciliar a idéia do princípio geral da democracia com o governo de elite formado pelos melhores membros da sociedade. ARBLASTER, op. cit., p.78. Sobre a teoria de J.S. Mill, ver também: MACPHERSON, op. cit., p.55 et seq. PATEMAN, op. cit., p. 35 et seq.

14 "O cidadão, segundo Bentham, deveria obedecer ao Estado na medida em que a obediência contribui mais para a felicidade geral do que a desobediência. A felicidade geral, ou o interesse da comunidade como um todo, deve ser entendida como o resultado de um cálculo hedonístico, isto é, a soma dos prazeres e dores do indivíduo. Assim, Bentham substitui a teoria do direito natural pela teoria da utilidade, afirmando que o principal significado dessa transformação está na passagem de um mundo de ficções para um mundo de fatos." PESSANHA, J.A.M. J.Bentham: vida e obra. In Os pensadores. São Paulo, Abril, 1979. p.VIII

15 Macpherson classifica as teorias democráticas antes do século XIX como utópicas. Estas seriam as precursoras da democracia liberal. Vide: MACPHERSON, op. cit., p.18

16 Estas franquias podem ser entendidas como privilégios especiais a alguns indivíduos. Bentham, no decorrer de sua vida, defendeu estas franquias de diversas maneiras. Num primeiro momento se colocava a favor de franquias limitadas que excluíam os trabalhadores, os não-instruídos, as mulheres e os dependentes. Mais tarde, defendeu uma franquia para chefes de família com casa própria e que pagassem impostos sobre a propriedade. E quando ele falou em uma franquia mais ou menos universal estavam excluídos os analfabetos, menores de idade $\mathrm{e}$ as mulheres.

17 J. S. Mill em Autobiography afirmava que não considerava mais a democracia representativa um princípio absoluto. Comentando sua posição da década de 1840, argumentava: "Éramos agora muito menos democratas do que eu já fora, porque, visto que a educação continua a ser tão abominavelmente imperfeita, passamos a recear a ignorância e principalmente o egoísmo e brutalidade das massas". MILL, J .S. Autobiography. Londres, Jack Stillinger, Oxford University Press, 1971. p. 138. Citado por: ARBLASTER, op. cit., p.77

18 Bobbio afirma que J.S.Mill também temia, assim como Tocqueville, a tirania da maioria. A sociedade devia se proteger desse mal.BOBBIO, N. Liberalismo e democracia. São Paulo, Brasiliense, 1988. p.68. Sobre a tirania da maioria em J. S. Mill, ver também: ALBLASTER, op. cit., p.78

19 Anthony Arblaster afirma que o livro A democracia na América "trata fundamentalmente da sociedade americana, não do seu governo ou sistema político." ARLBASTER, op. cit., p. 21 


\section{REFERÊNCIAS BIBLIOGRÁFICAS}

ARBLASTER, A . A democracia. Lisboa, Estampa, 1988.

BENTHAM, J. Uma introdução aos princípios da moral e da legislação. São Paulo, Abril, 1979. Coleção Os pensadores.

BOBBIO, N. A teoria das formas de governo. Brasília, UNB, 1980. p.120

Id., Liberalismo e democracia. São Paulo, Brasiliense, 1988.

DUVERGER, M. As modernas tecnodemocracias. Rio de Janeiro, Paz e Terra, 1975.

GRUPPI, L. Tudo começou com Maquiavel. Porto Alegre, LP\&M, 1985.

JEFFERSON, T. Escritos políticos. São Paulo, Abril, 1979. Coleção Os pensadores.

HAMILTON, A . Os federalistas. São Paulo, Abril, 1979. Coleção Os pensadores.

HOBSBAWN, E. As forças da democracia. A era do capital. Rio de Janeiro, Paz e Terra, 1982.

MACPHERSON, C. B. A democracia liberal. Rio de Janeiro, Zahar, 1978.

MADISON, J. Os federalistas. São Paulo, Abril, 1979. Coleção Os pensadores.

MARSHALL, T. H. Cidadania, classe social e status. Rio de Janeiro, Zahar, 1967.

MILL, J. S. Governo representativo. São Paulo, Ibrasa, 1964.

MONTESQUIEU, C. O espírito das leis. São Paulo, Abril, 1973. P.69-85. Coleção Os pensadores.

PATEMAN, C. Participação e teoria democrática. Rio de Janeiro, Paz e Terra, 1992. p.35
SARTORI, G. Teoria democrática. Lisboa, Fundo de Cultura, 1965.

ROUSSEAU, J. J. Discurso sobre a origem e os fundamentos da desigualdade entre os homens. São Paulo, Cultrix, 1978.

Id., O Contrato social. São Paulo, Cultrix, $1978^{\mathrm{a}}$.

TOCQUEVILLE, A . de. A democracia na América. Belo Horizonte, Itatiaia, 1977. 